\title{
Introduction
}

\section{Alberto Alemanno}

The specific analytical focus of the volume is the notion of emergency risk regulation, i.e. regulatory action undertaken in the immediacy of a disaster in order to mitigate its impact. By retrospectively looking at what happened during the European volcanic ash crisis and other recent contingencies, contributors from a variety of disciplines - including sociology, economics, political science, moral philosophy, management, risk analysis and law - consider the regulatory dilemmas characterizing emergency risk situations. The objective of this edited volume is twofold: (1) understanding which are the main features and challenges of emergency risk regulation; (2) examining the use of scientific advice and evidence when authorities are put under great pressure to deal with atypical situations. Moreover, this volume also has a wider goal. By generalizing some of the most salient features of the volcanic ash crisis and other recent emergencies, this book proactively suggests how the lessons learned can affect other regulatory systems that might be faced with similar emergencies.

The recent European volcanic ash crisis epitomizes the general problem of emergency response in a world of uncertain manufactured and natural risks. A cloud of volcanic ash preventing travelling across an entire continent probably neither featured in the risk-management scenarios of many firms nor in the contingency plans of public authorities. Therefore, it is of no surprise that the immediate and drastic regulatory response that followed soon became an uneven political dispute between industry economic power and regulatory science, with consumers caught in the middle. Regulatory systems designed for careful deliberation and cooperative action had to respond almost instantly to a barrage of scientific data arguments and conflicting legal interpretations, with threats of litigation on one side and the risk of loss of human life on the other.

The ash crisis is not the first or the only such problem to have occurred. It is one of a series of recent real or potential catastrophes - natural disasters, terrorist attacks, and pandemics - that have taken by surprise globalized firms and regulators. As such it represents a rich case study in the problem of emergency risk regulation and the questions that it raises 
should concern a wide variety of scholars, regulators and industry analysts whose normal areas of concern are far removed from aviation and volcanoes. Any industry could face a problem that involves the same rapid, fragmented and multi-layered regulatory response. Some industries may even encounter problems or situations that are even more complex than the ash crisis. Indeed, potentially devastating crises loom on the horizon (Boin, 2010; Rosenthal et al., 2001). According to many, the volcanic eruption, as well as the recent 2011 Japanese tsunami, will serve as a wake-up call for both companies and regulators that need to modernize their understanding of the risk management approaches aimed at averting disasters or mitigating their full effects.

How to respond to such emergency problems is a major source of complexities in risk analysis, crisis management, regulatory decisionmaking and, more in general, in any legal system. Hence, a growing international community of scholars coming from different disciplines recognize this problem and is beginning to examine and discuss the interlocking structures of governance and regulation that pertain to disasters (Ansell et al., 2010; Farber and Fauré, 2009; Bostrom and Cirkovic, 2008). This emerging field of study encompasses diverse and interdisciplinary areas of research, ranging from central normative issues of disaster law to technical crisis management systems as well as issues of institutional design in disaster prevention (Disaster Law and the Legal Academia, 2007). It also includes empirical research areas of risk and decision-making.

Is rational decision-making possible in a situation of emergency? How to determine a proportionate response to risk events? Who is competent to conduct the assessment of the hazard? Who is competent to take risk-management decisions? What is the role of government in an emergency situation? Who has the final word on the quality of the safety analysis? Does industry ignore the problem until it finally occurs? How accurate are estimates of costs and benefits? Which risks are insurable? Do regulators tend to overact? What if they do? To what extent do they manage a politically perceived risk rather than the actual one? What are the implications of different schools of technical thought that must be resolved by the regulator? How and by whom should risks be communicated? Which are the consequences stemming from bad emergency regulations adopted in a high stress environment?

The chapters that follow address these questions. Their authors are intentionally drawn from different disciplines, such as sociology, economics, political science, moral philosophy, management, risk analysis and law, in order to provide an original perspective on emergency risk regulation. While literature in the business management field often amounts to 'rules for effective crisis management', most other disciplines, 
such as Disaster Law and Policy and Risk Regulation, are sceptical that generic rules can be applied to each and every extraordinary event.

Before leaving you to the individual chapters gathered in this book, I would like to offer the reader some background. To this purpose, the next sections discuss the 'what, when and how' of emergency risk regulation.

\section{WHAT IS EMERGENCY RISK REGULATION}

In choosing as the analytical focus of the book the notion of emergency risk regulation, it is first necessary to address the question of what do we mean for 'emergency risk regulation'. This rubric encompasses virtually all regulatory actions undertaken in the immediacy of a disaster in order to mitigate its impact. On this definition, an immensely diverse collection of regulatory interventions could constitute emergency risk regulations: potential candidates include anti-seismic regulations, radiation safety standards, pandemics response plans, and disaster management. If the concept of risk characterizes a 'peculiar, intermediate state between security and destruction' (Beck, 2000), in an 'emergency risk' the balance between these two clearly tilts for the latter. As for any risk situation, emergencies call for more public than private action.

Being triggered by a disaster, emergency risk regulation presupposes the existence, or a mere threat, of a disaster. A disaster is a natural or man-made hazard resulting in an event of substantial extent causing significant physical damage or destruction, loss of life, or drastic change to the natural environment. A disaster can be generally defined as any tragic event with great loss stemming from events such as earthquakes, floods, catastrophic accidents, fires, or explosions. Yet as exemplified by both the 2010 volcanic ash crisis and the 2011 Japanese tsunami the lines between manufactured and natural risks are increasingly blurred.

Typically, one speaks of crisis or disaster when a threat is perceived against the core values or life-sustaining functions of a social system, which calls for urgent remedial action under conditions of uncertainty (Rosenthal et al., 1989). Yet although the category of disaster at first may seem unproblematic it is an elastic concept centred on the following commonplace three-part characterization: sudden, significant and natural (Dauber, 1998; Caron 2001). Suddenness is the most relevant criterion to define a disaster for the purposes of emergency regulation. It emphasizes the emergency dimension triggered by the catastrophe in its destabilizing influence on the social, physical and institutional infrastructure of a given community. As for significance, the significant risk of harm associated with disasters is different from what we typically experience in times of normalcy. As a result, determination of an event as 'disaster' may produce 
significant impact on the regulatory context by justifying the partial or total suspension of the ordinary decision-making process (Gerrard, 2006). Such departures from the rule of law, or simply from established procedures, are generally perceived as necessary if the 'significance' threshold has been met by the relevant event. Moreover, the relative importance given to a disaster by policy-makers and the public at large may vary according to the social values. In particular, prejudicial attitudes, often based on a long-standing socio-economic or racial bias, may influence disaster response systems as well as timelines (Dauber, 1999).

As for naturalness, there is growing agreement - reinforced by the Japanese emergency situation triggered by an earthquake followed by a tsunami and a nuclear safety emergency - that even the damage caused by naturally-occurring events, such as a tsunami or a volcanic eruption, is inextricably bound with human agency, thus making it impossible to distinguish between a man-made and a natural disaster (Farber et al., 2010). As illustrated by the volcanic ash crisis as well by the recent Japanese tsunami, "physical phenomena are a necessary component of risk, but they are only the starting point in addressing safety concerns' (Farber, 2006).

\section{WHEN IS THE TIME FOR EMERGENCY RISK REGULATION}

Emergency risk regulation finds its natural regulatory space within the first two stages of the disaster cycle: mitigation and emergency response. In principle, mitigation efforts attempt to reduce the potential impact of a disaster before it strikes, while disaster response tends to do so after the event. Yet, as exemplified by the volcanic ash crisis, the distinction between emergency mitigation and emergency response is not always so sharp. When called upon to act under the threat of a catastrophe, the authorities happen to both mitigate and respond to such a threat in a situation characterized by suddenness (emergency) and significance.

As a result, emergency risk regulation is not directly interested with the other phases of the cycle. In particular, it does not operate in the disaster prevention phase (often defined 'crisis management') nor in those final stages, collectively called post-disaster assistance, such as insurance/ liability compensation, government assistance and rebuilding.

Although there is a tight linkage between the various risk management categories, emergency risk regulation is clearly called to operate in the initial phase of the disaster cycle, when the mere menace of a disaster overshadows the regulatory context by emergency. This is where media and public attention tend to focus. As a result, a vital part of emergency 
risk regulation is represented by risk communication along the disaster cycle. In particular, in an emergency, the need of communicating risk effectively to the public is crucial to prevent distrust and anxiety. To this purpose a recent report by the Science and Technology Committee of the UK House of Commons recommends public authorities, while communicating emergencies to the public, to rely on the concept of 'most probable scenarios' rather than on the actual government's policy of 'reasonable worst case scenarios' (House of Commons, Science and Technology Committee, 2011). In any event, there is a need to strike a balance between confidentiality and disclosure when preparing for, and responding to, emergencies.

\section{FEATURES OF EMERGENCY RISK REGULATION}

In the immediacy of any disaster, industry representatives, public authorities, decision-makers at every level of government must mitigate and respond to disasters through emergency risk regulation. As a result, emergency risk regulation, by taking place in the immediacy of a disaster, is characterized by the following features: (1) it is triggered by (the threat of) an unpredictable, sudden and significant event; (2) it occurs under time pressure and in a situation characterized by uncertainty; (3) it reflects, being shaped by prevalent interests and public attitudes, a prevalent narrative; (4) it is often characterized by transnational nature, as it addresses transboundary risks spreading across jurisdictional borders and policies boundaries; (5) it requires, and is conditioned by, emergency risk communication, as it multiplies the need for fast and effective information; (6) it questions the applicability of existing regulatory schemes, even those that expressly codify an emergency response to risk.

\section{Unpredictable, Sudden and Significant Event}

The event typically triggering emergency risk regulation is the threat of a disaster, i.e. a natural or man-made hazard resulting in an event of substantial extent causing significant physical damage or destruction, loss of life, or drastic change to the natural environment. As mentioned above, it is not only the significance of the risk that differentiates a disaster from a non-disaster event, but also its suddenness. As a result, public leaders, being caught by surprise by these events, typically qualify emergencies caused by a disaster as unthinkable and impossible to foresee. Due to its unpredictable character, the manifestation of a disaster, or the threat of its appearance, tends to be characterized by its abruptness. These features (unpredictability and abruptness), which have been defined as being of 'Hollywood quality', trick the imagination and contribute to make emergencies difficult to recognize in time (Boin, 2010). 
Both the suddenness and abruptness surrounding any disaster scenario presents emergency risk regulation with the challenge of 'paralysis in decision-making'. This paralyzing situation can also be caused by the immediate and on-going search for better information typical of an emergency. In turn, this may give rise to a cascade of incoming data that are difficult to interpret. To avoid such a paralyzing effect of emergencies, Chad Briggs (Chapter 11) illustrates the potential use of scenario planning, a risk emergency tool aimed at creating systematic decision-making through decisions that can be made in advance concerning potential contingencies and disasters. Also, Lorenza Jachia and Valentin Nikonov (Chapter 10) illustrate that paralysis in decision-making due to emergency situations can be overcome by elaborating contingency plans. In particular, they identify issues that regulators should consider when designing, testing, implementing and maintaining crisis management plans and developing legislation that covers situations of emergency. They argue that actions taken by regulators in the immediacy of crisis will only be effective if the regulatory system embraces all functions of the riskmanagement process. Yet an abundant literature shows that plans, even disaster plans, work well for predictable and well-known events, not for those capable of generating emergencies situations. This is because the suddenness, abruptness and lack of information and coordination typical of emergencies make it impossible to control 'each and every move of first responders', especially in the initial phase of an emergency (Boin, 2010). Far from being useless, crisis planning may not only induce a false sense of security, but also - more critically - may reduce the imagination, creativity and flexibility that are badly needed during an emergency situation (Clarke, 1999). Along these lines, Giuliano Castellano (Chapter 16) attempts to identify the core policy issues to be addressed through a risk-based governance model that stimulates preventive strategies and minimizes losses. In particular, he illustrates how changing policy objectives might lead to establish a correct set of incentives that - with different insurance and reinsurance techniques - helps to reduce the impact of unexpected events ensuring a recovery of large-scale losses.

\section{Time Pressure and Uncertainty}

Another feature of emergency risk regulation is uncertainty and the lack of suitable scientific evidence. Typically, in times of emergency, uncertainty, interpreted as discordance between facts and beliefs, intensifies. This is because, in emergencies, hazards tend to be mutable, not static, and rumours and incorrect information make it difficult to understand the nature of the hazard. In those circumstances, any regulatory effort is hampered by the lack of knowledge as to the hazard at stake and, more critically, about the actual and potential consequences stemming from it. 
As a result, risk managers typically find it hard to collect, share and interpret the right information (Boin, 2010). In particular, the scientific evidence underpinning regulatory action instead of stemming from 'normal science' tends to be derived from 'secret and often inadequately tested approaches that are routine in forensic science', i.e. any scientific enterprise whose primary market is the legal and regulatory system (Brannigan, Chapter 7). No surprise that the use and misuse of this science instead of 'normal science' may lead to suboptimal results. Moreover, the lack of adequate information makes it difficult to weigh the possible consequences of a 'false positive' (i.e. investing resources in a non-event) against those of a 'false negative (i.e. ignoring a crisis) (Boin, 2010). All of these aspects are compounded when there are few recognized transEuropean frameworks for the exchange of credible scientific advice (Olson, 2009). Thus in the European volcanic ash crisis, individual member states relied on input from different scientific experts who provided inconsistent and partial advice. In consequence, as shown by Chris Johnson and Alain Jeunemaitre's chapter (Chapter 4), it took extraordinary intervention on behalf of the European Transport Council to cut through the ad hoc applications of the precautionary principle. A key finding from this work is that we need to prepare a framework for the involvement of leading scientific advice if we are to avoid any repetition in further contingencies. Yet - given the transboundary nature of most of those emergency risks - rapidly to share information and coordinate regulatory action under the threat of a catastrophe is a challenge in itself (Ansell et al., 2010).

If epistemic uncertainty (i.e. lack of understanding of basic rules of nature), aleatory uncertainty (i.e. lack of adequate data for use in analysis) and intentional (i.e. lack of knowledge of human intentions) uncertainties characterize risk regulation, it is normative uncertainty that causes more concern in emergency regulation. As illustrated by A.M. Viens in Chapter 9 drawing on moral philosophy, normative uncertainty (i.e. lack of consensus as to the truly desired social course of action) may 'prolong the intensity or duration of the emergency, since the diminished ability of the regulation to coordinate and regulate the behaviour of the 'regulatees' means that regulators will have less time and resources to devote to the source of the emergency itself'. In his view, since normative uncertainty exists to a much higher degree in times of emergency, the regulators should take into account its moral significance. Critically, normative uncertainty increases the possibility that conventional moral standards may or may not hold up in the same way. Likewise, because of uncertainty, any act of balancing between conflicting values, such as safety and economic reasons, may be exacerbated in an emergency situation. Indeed, one may doubt whether in emergency circumstances 
often characterized by the threat of a catastrophe an act of balancing between safety and economic reasons (i.e. continued operations) is likely to be biased in ways that ought to be recognized and account for. In particular, the pressures exercised on the decision-maker combined with certain unique features of crisis mind-set may result in systematic undervaluation of one interest and overvaluation of another so that the resultant balance would be tilted in favour of safety concerns at the expenses of economic or other concerns. This shows that when regulating under emergency risk situations there exist certain challenges to the rational actor model. Indeed, according to cognitive psychologists, individuals are subjects to cognitive heuristics, i.e. shortcuts that people use when making decisions, as a means of countering the lack of sufficient time to properly assess the situation (Twersky and Kahneman 1974, 185). This typically occurs when individuals, and also decision-makers, make decisions under conditions of risk and uncertainty. Decision-making that takes place under conditions of uncertainty caused by emergency is particularly prone to suffer from distortions that result from the interplay of informational and reputational influence and cascades (Burgess, Chapter 5; Chakraborty, Chapter 6). Indeed these intuitive rules of thumb typically shape people's judgment under uncertainty, and often in ways that contravene the norms of the probability theory ('probability neglect') (Slovic, 2000; Sunstein and Zeckhauser, 2010). Hence, the concern, shared by a significant number of risk regulation authors that biased risk perceptions may be reproduced in public policy, law and regulation by governments responsive to the demand of its citizens (Sunstein, 2005; Eskridge, 2002). The question on how better to use the results of cognitive theory in regulating risk remains open, yet high, on the agenda of several countries today (Eskridge et al, 2002; Obama, Executive Order 13563, 2011).

\section{Prevalent Interests and Public Attitude Shaping a Prevalent Narrative}

Staged risk shapes its perception and inevitably its reaction (Beck, p. 137 ss). In particular, media set the stage on which the performance of risk managers is assessed in the aftermath of the emergency (Boin, 2010). Yet public leaders are not the only ones trying to frame an emergency situation. Their messages compete with those of other actors, who - as they typically hold diverging interests - depict the ongoing crisis differently and support alternative courses of action (Sunstein, 2007). Both prevalent interests and public attitudes about risk might indeed influence the emergency risk regulation that will be enacted, given that political officials, in their pursuit for political security, seek to gratify the preferences of their more vocal or powerful constituencies (Noll and Krier, 2000; Downs, 1957). This might give rise to the problem of the 'omitted 
voice', wherein the interests, values and preferences of stakeholders are disregarded from the decision-making process, often with the result that they will endure the damage, be it of economic or health nature, stemming from regulatory action or inaction (Graham and Wiener, 1996). In particular, in an emergency, well-connected parties may exploit epistemic and normative uncertainty to circumvent burdensome safety requirements and avoid transparent science in the regulatory process. As illustrated by Vincent Brannigan, they may do so by trying to reverse the burden of proof and make regulators prove the hazard rather than the industry prove safety (Brannigan, Chapter 7). In his view, this is what occurred in the volcanic ash crisis. Here the shift of burden of proof from the industry to the regulators and acceptance of 'substandard evidence' marked a 'paradigm shift' that redefined the regulatory environment. The concept of paradigm shift has been and remains a topic of major debate in the history and philosophy of science and seems particularly promising in the analysis of emergency risk regulation (Kuhn, 1962; Casti, 1990). In turn, not only prevalent interests but also media reporting shape public attitudes. In an emergency situation, the media are central to determining the outcome of government efforts as well as the crucial post-event perception of their adequacy (Rosenthal, Boin and Comfort, 2001). Although media coverage is often ill suited for 'sustaining high level coverage of long-term threats' (Kitzinger and Reilly, 1997), it plays an active role in framing risk controversies and can stigmatize technological risks (Flynn, Slovic, and Kunreuther, 2001). In particular, medias can generate an amplification of risk, perpetuating public distrust (Lofstedt and HorlickJones, 1999). In this type of environment where misperception is mounting, trust plays a considerable role in public perceptions of the severity of risk (Siegrist and Cvetkovich, 2000). Yet, as illustrated by Adam Burgess (Chapter 5) and Donald Macrae (Chapter 2), the demand for safety or feelings of distrust were not particularly acute in the volcanic ash crisis. The issue never became salient enough to trigger a phenomenon of 'social amplification of risk' (Sunstein, 2007). In particular, Burgess, by categorizing the stories generated by the ash cloud, illustrates how coverage of this emergency risk did not extend, despite the uncertainty inherent in the crisis, far beyond the immediate impact made by the cloud. In his view, this outcome confirms that the representation of hazards as significant risks remains contingent upon the nature of the hazard (an 'act of God' here) and its legacy as well as the context in which it becomes manifest (lack of major accidents). Although it would have been quite easy to spin the crisis and contribute to make it gain momentum thus generating unwarranted concerns, this did not occur. This would prove that there exist limits to the ability of the media, also in a situation of emergency regulation, to do so. 


\section{Transnational Character due to the Increasing Transboundary Nature of the Risks}

As more and more citizens come to reap the benefits of open trade on a global scale, as well as extended lifespan and high quality of life, they also seem to expect public authorities to deliver more protection against threats to health, safety and the environment (Alemanno, 2011). Yet due to their inherent global dimension, risks today call for global and coordinated governance solutions. In particular, due to the increased world interconnectedness and rapid technological development, emergencies are increasingly becoming transboundary in nature. As such they affect multiple jurisdictions, they undermine the functioning of various policy sectors and evolve rapidly. Moreover, due to their nature, those risks tend to involve more participants who tend to be dispersed and struggle to share information and coordinate their actions. New forms of large-scale disasters, usually defined as emerging systemic (or catastrophic) risks, have gained more attention at international level, as the frequency of these occurrences increased and policy actions are required to prevent and minimize losses (OECD, 2003; Castellano, 2010).

It is against this backdrop that the very legitimacy, accountability and effectiveness of emergency regulatory action are increasingly measured today. Indeed, being modernity an enterprise for constructing order and control, transboundary risks call this very assertion of control by the nation-state into question today. Indeed the institutional and administrative structures for responding to emergency situations are not designed to deal with transboundary scenarios. In particular, their administrative toolbox for routine problems is of limited use in dealing with transboundary emergencies (Lagadec, 1990). Moreover, as illustrated by several social studies of scientific knowledge production, risks are culturally constructed, socially contested, and differently perceived not only across societies but also across time and space (Jasanoff, 1990; Wynne and Dressel, 2001). As a result, different countries have shown to possess significantly diverse cultures of scientifically informed regulation (Jasanoff, 1993). This poses governments the challenge to rationalize decisionmaking and urgently call them to coordinate their regulatory actions. Transboundary risks accentuate the challenges that public and private authorities confront in the face of urgent threats, and as such they represent a further experiment for emergency risk regulation (Ansell et al., 2010). An in-built tension in the EU relates to the division of responsibilities between the national and the EU-level. Being crisis management issues are regarded as the core responsibility of the nation-state by the citizens of the EU member states, European political leaders are in many instances unwilling to surrender policy-making autonomy in exchange for 
coordination at the EU-level (Olsson, 2009). Interestingly enough, the EU member states have included a 'Solidarity Clause' in the Treaty of Lisbon, thus introducing a legal basis for institutionalizing emergency risk regulation in the EU legal order. This provision (article 222) reads: 'The Union and its Member States shall act jointly in a spirit of solidarity if a Member State is the object of a terrorist attack or the victim of a natural or man-made disaster' (Consolidated Version of the Treaty on the Functioning of the European Union, 2009).

By drawing on the literature on organizational studies of risk and regulation, Christopher Lawless (Chapter 15) argues that a holistic, integrated and sociologically oriented approach is needed to understand risk regulation, especially in an increasingly global context. By taking as a point of departure in his analysis the volcanic ash crisis, he discusses how localized risks may become transformed into transboundary risks through organizational dynamics.

In turn, Francisco Lopez-Jurado (Chapter 12), by focusing on the European regulatory framework of network industries, discusses the systemic nature of transboundary risks. In his view, the concept of 'systemic risk' rapidly exceeded the boundaries of the financial sector, as a 'side-effect' of globalization, or as an intrinsic consequence of the multiplication of highly complex interconnected systems. He concludes that the balkanized structure of EU law concerning air transport and energy, in addition to the balance of power between EU institutions and the member states, should be re-examined in order to provide better responses to systemic risks affecting network industries.

\section{Communicating with the Public}

Risk communication, i.e. providing information on levels of health, safety and environmental risks, their significance and their management, is a critical component of effective emergency response, especially when dealing with a high perceived risk event. Indeed, the way an emergency is communicated to the public tends to influence the final emergency risk regulation. In general risk communication is concerned with the effectiveness with which messages are presented to the public: are they understandable? Do they under- or over-simplify?

Essentially, communicating risks may take many forms, such as written, verbal or pictorial. As such, it may include a wide range of different sources of information and may involve many different types of organizations (Covello et al., 1988). The raison d'être of risk communication within the broader framework of risk regulation lies in the assumption that scientific results as well as risk management options cannot always be easily converted into simple guidelines and advice that non-scientists, like the public or the media, can easily understand or follow. This seems 
especially true at a time in which we learn about crises via new media tools, such as Twitter, Facebook and YouTube. Moreover, public opinion having become more sceptical about the neutrality and effectiveness of science, there is a growing call for more transparency, especially in times of emergencies. Indeed, pre-existing distrust in government does not vanish in times of crisis. Moreover, in a typical emergency crisis, due to the significant number of actors involved, it is hard to produce one clear and univocal message capable of relieving collective stress. Against this backdrop, Sweta Chakraborty (Chapter 6), placing herself at the interface between risk communication and risk perception research, first highlights the main challenges existing in emergency risk communication. Second, she ventures to provide a plausible blueprint for the best risk communication strategy in emergency situations. In so doing, she illustrates how emergency communication approaches developed from previous similar borderless threats (i.e. pandemics and terrorist attacks) and how such lessons learned were not anticipated and adapted for the type of crisis presented in this book.

Even in the immediacy of disasters, it is evident that peoples' judgment and decision-making processes must be taken into account in order to produce effective risk communications. Today it seems undisputed that the current most widely accepted best practice approach towards risk communication in emergency situation is to first understand how lay publics cognitively perceive risks. Yet, notwithstanding the existence of this sophisticated body of knowledge, public leaders and risk managers often fail to recognize the importance of media in times of emergencies (Macrae, Chapter 2).

\section{Challenge to Existing Regulatory Schemes}

The institutional structures, legislative schemes and administrative processes for crisis and disaster management are periodically subject to 'stress tests' in each and every emergency situation. This is generally due to the fact that it is hard, from both an institutional design and normative point of view, to predict unforeseen and unimagined events. On the one hand, planning for each possible threat of hazard that may occur may lead not only to overspending but also to too detailed planning. On the other hand, adopting broader regulatory frameworks can lead to abstract schemes that may fail to provide guidance during an emergency. Yet an emergency requires some form of action, generally with great urgency and involving the possibility of unintended consequences. Moreover, as discussed in Christopher Lawless' chapter (Chapter 15), the transboundary nature of more and more emergencies renders even more difficult the task to design effectively a regulatory response to crises. In this context, Alfredo Fioritto and Marta Simoncini (Chapter 8) argue that given the 
difficulty in assessing the 'if and when' of catastrophes, due to a lack of scientific knowledge towards disasters, science-based risk regulation is not the optimal solution. They thus recommend the use of standard-based risk regulation that strikes a balance between the state's duty of protection from catastrophes, the exercise of fundamental rights and the costs of implementing the regulation. This 'Pareto optimum' - or acceptable level of protection - represents the point up to which a state is willing to or allowed to protect without constraining too much an individual's liberty.

The EU Air Passengers' Rights Regulation aimed at protecting passengers flying within Europe in case of boarding denial, delay and cancellation was unequivocally challenged by the volcanic ash crisis. When drafting this Regulation the EU legislator unambiguously anticipated having it covering both ordinary and extraordinary circumstances. However, the Icelandic ash cloud, as noted by Morten Broberg (Chapter 13), was not merely extraordinary; rather it brought about exceptional circumstances, or, to be more precise, it produced an emergency situation. In examining the application of the Air Passengers' Regulation in emergency situations like the one experienced during the ash cloud, Morten Broberg and Nick Bernard (Chapter 14) illustrate the limits to the legislator's ability to predict, respond and institutionally design effective protective emergency risk regulation coping with unusual, unforeseen and unimagined events. Both authors seem to agree that when it comes to emergency situations like the one experienced during the Icelandic ash cloud, the present Regulation provides an inadequate scheme for achieving its declared goal of consumer protection. At the time in which the EU legislator is laying down dedicated regulations aimed at recognizing passengers' rights also in the road and maritime transport sectors, they recommend a set of original and insightful suggestions for a possible reform of the Air Passengers' Rights Regulation. The Commission has recently unveiled its plans to draw the necessary lessons from the crisis and, after conducting an impact assessment evaluating further possible measures, is likely to revise the Regulation (Council of the European Union, 2011).

\section{STRUCTURE OF THE BOOK}

After this introductory chapter setting up the general framework of the volume, the first part aims at describing the volcanic ash crisis and to explain the lessons learned. The second describes the ideologies, narratives and communication challenges of emergency regulation. The third part goes beyond the ash crisis itself and addresses the many facets of emergency regulation. Whereas part four will be devoted to the organizational mechanisms of emergency regulation, some examples of codified 
emergency regulation will be dealt with in part five. Finally, part six suggests several new ideas for emergency risk regulation, and a closing chapter critically concludes the volume with a modest set of recommendations on how to regulate risk in emergencies. Each of the chapters ends with some references to the literature for those who wish to learn more in that specific sub-field of risk research.

\section{BIBLIOGRAPHY}

Alemanno, A. (2012), 'Regulating the European Risk Society', in A. Alemanno, F. den Butter, A. Nijsen and J. Torriti, Better Business Regulation in a Risk Society, Springer, forthcoming (2012).

Alexander, D. (2002), Principles of Emergency Planning and Management, New York: Oxford University Press.

Ansell, C., A. Bojn and A. Keller (2010), 'Managing Transboundary Crises: Identifying the Building Blocks of an Effective Response System', Journal of Contingencies and Crisis Management, 18 (4), 195-207.

Beck, U. (1992), Risk Society: Toward A New Modernity, London: Sage Publications.

Beck, U. (1999), World Risk Society, Cambridge: Polity Press.

Beck, U. (2000), 'Risk Society Revisited', in B. Adam, U. Beck and J. van Loon, The Risk Society and Beyond: Critical Issues for Social Theory, London: Sage, pp.211-29.

Boin, A. (2010), 'Preparing for Future Crises: Lessons from Research', in B. Hutter, Anticipating Risks and Organising Risk Regulation, Cambridge: Cambridge University Press, pp. 231-48.

Boin, A. and P. 't Hart, E. Stern and B. Sundelius (2005), The Politics of Crisis Management: Public Leadership Under Pressure, Cambridge: Cambridge University Press.

Boin, A. and M. Rhinard (2008), 'Managing Transboundary Crises: What Role for the European Union', International Studies Review, 10, 1-26.

Bostrom, N. and M.M. Cirkovic (2008), Global Catastrophic Risks, Oxford: Oxford University Press.

Brannigan, V. (2010), 'Alice's Adventures in Volcano Land: The Use and Abuse of Expert Knowledge in Safety Regulation', European Journal of Risk Regulation, 1 (2), 107-14.

Canton, L. (2007), Emergency Management: Concepts and Strategies for Effective Programs, New Jersey: Wiley.

Caron, D.D (2001), 'Addressing Catastrophes: Conflicting Images of Solidarity and Self Interest', in David D. Caron and Charles H. Leben (eds), Les Aspects Internationaux des Catastrophes Naturelles et Industrielles/The International Aspects of Natural and Industrial Catastrophes, The Hague Academy of International Law.

Castellano, G. (2010), 'Governing Ignorance: Emerging Catastrophic Risks Industry Responses and Policy Frictions', The Geneva Papers, 35, 391-415.

Casti, J.L. (1990), Paradigms Lost, Harper perennial. 
Clarke, L.B. (1999), Mission Improbable: Using Fantasy Documents to Tame Disasters, Chicago: University of Chicago Press.

Consolidated Version of the Treaty on the Functioning of the European Union (2009).

Council of the European Union (2011) 'EU Volcanic Ash Crisis: Follow-Up and the Wider Scope of Crisis Management', Information from the Commission, March 25, 2011.

Covello, von Winterfeldt, and Slovic (1986), cited in OECD, Risk Communication Chemical Product Risks - An OECD Background Paper, Berlin, 2000.

Farber, D.A. and M. Fauré (2010), Disaster Law, Cheltenham, UK and Northampton, MA: Edward Elgar.

Farber, D.A, R.G. Bea, K. Roberts, E. Wenk and K. Inkabi (2006), 'Reinventing Flood Control', Tulane Law Review, 81 (1085).

Dauber, M.L. (1998), 'Let Me Be Next Time "Tried By Fire": Disaster Relief and the Origins of the American Welfare State', Northwestern University Law Review, 92, 967-71.

Dauber, M.L. (1999), 'Fate, Responsibility and 'Natural' Disaster Relief: Narrating the American Welfare State', Law \&Society Review, 33, 257-61.

Disaster Law and the Legal Academia (2007), 'Curriculum, Research and Law Reform', Report on a Workshop held at UC Berkeley Law School, 25 June 2007.

Downs, A. (1957), An Economic Theory of Democracy, New York: Harper.

Drennan, L.T. and A. McConnell (2007), Risk and Crisis Management in the Public Sector, New York: Routledge.

Eskridge, W.N. Jr. and J. Ferejohn (2002), 'Structuring Lawmaking to Reduce Cognitive Bias: A Critical View', Cornell Law Review, 87, 616.

Flynn, J., P. Slovic and H. Kunreuther (2001), Risk, Media and Stigma; Understanding Public Challenges to Modern Science and Technology, London, Sterling, VA: Earthscan.

Gerrard, M.B. (2006), 'Emergency Exemptions from Environmental Laws After Disasters', Natural Resources \& Environment, 20 (10), 10-14.

Graham, J. and J. Wiener (1996), Risk versus Risk: Tradeoffs in Protecting Health and the Environment, Cambridge, MA: Harvard University Press.

Hood, C., H. Rothstein and R. Baldwin. (2001), The Government of Risk: Understanding Risk Regulation Regimes, Oxford: Oxford University Press.

Hutter, B.M. (2010), Anticipating Risks and Organising Risk Regulation, Cambridge: Cambridge University Press.

Hutter, B.M. and M. Power (2005), 'Organizational Encounters with Risk: An Introduction', in B.M. Hutter and M. Power (eds), Organizational Encounters with Risk, Oxford: Oxford University Press, 1-32.

House of Commons, Science and Technology Committee, Scientific advice and Evidence in Emergencies, Third Report of Session 2010-11, February 2011.

Jasanoff, S. (1990), The Fifth Branch: Science Advisers as Policy Makers, Cambridge, MA: Harvard University Press.

Jasanoff, S. (1993), 'Bridging the Two Cultures of Risk Analysis', Risk Analysis, 13 (2), 123-9.

Kitzinger, J. and J. Reilly (1997), 'The Rise and Fall of Risk Reporting', European Journal of Communication, 12(3), 319-50.

Kuhn T.S. (1962), The Structure of Scientific Revolutions, Chicago: Univ. of Chicago Press. 
Lagadec, P. (1990), States of Emergency: Technological Failures and Social Destabilization, London: Butterworth-Heinemann.

Löfstedt, R.E. and T. Horlick-Jones (1999), 'Environmental Regulation in the UK: Politics, Institutional Change and Public Trust', in G. Cvetkovich and R.E. Löfstedt (eds), Social Trust and the Management of Risk, London: Earthscan, 73-88.

Majone, G. (1984), 'Science and Transcience in Standard Setting', Science, Technology and Human Values, 9 (1), 15-22

Noll, R.G. and J. E. Trier (2000), 'Some Implications of Cognitive Psychology for Risk Regulation', in C.R. Sunstein, Behavioral Law \& Economics, Cambridge: Cambridge University Press.

Obama, B. (2011) Executive Order 13563 of January 18, 2011, Improving Regulation and Regulatory Review.

OECD (2003), Emerging Systemic Risks in the 21st Century: An Agenda for Action, Paris: OECD.

Olson, S. (2009), Crisis Management in the European Union-Cooperation in the Face of Emergencies, Berlin-Heidelberg: Springer.

Posner, R.A. (2004), Catastrophe: Risk and Response, New York: Oxford University Press.

Rosenthal, U., R.A. Boin and L.K. Comfort (eds) (2001), Managing Crises: Threats, Dilemmas, Opportunities, Springfield: Charles C. Thomas.

Siegrist, M. and G. Cvetkovich (2000), 'Perception of Hazards: the Role of Social Trust and Knowledge', Risk Analysis, 20, 713-9.

Slovic, P. (2000), The Perception of Risk. London: Earthscan Publications.

Smith, D. and D. Elliot (2006), Key Readings in Crisis Management: Systems and Structures for Prevention and Recovery, New York: Routledge.

Sunstein, C.R. (2000), Behavioral Law \& Economics, Cambridge: Cambridge University Press.

Sunstein, C.R. (2005), Laws of Fear: Beyond the Precautionary Principle, Cambridge: Cambridge University Press.

Sunstein, C.R. (2007), Worst-Case Scenarios, Cambridge, MA: Harvard University Press.

Sunstein, C.R. and R. Zeckhauser (2010), 'Dreadful Possibilities, Neglected Probabilities', in E. Michel-Kerjan and P. Slovic (eds), The Irrational Economist, New York: Public Affairs Press.

Twersky, A. and D. Kahneman (1974), 'Judgement under Uncertainty: Heuristics and Biases', Science, 185 (4157), 1124-31.

Weinberg, A.M. (1985), 'Science and its Limits: The Regulator's Dilemma', Issues in Science and Technology, 2 (1), 59-72.

Wynne, B. and K. Dressel (2001), 'Cultures of Uncertainty - Transboundary Risks and BSE in Europe', in J. Linnerooth-Bayer, R. Lofstedt and G. Sjostedt (eds), Transboundary Risk Management, London: Earthscan, 121-54. 